NOTES

\title{
Phase Transfer Catalyzed Polycondensation of Bishalomethyl Aromatic Compounds
}

\author{
Noboru YAMAZAKI and Yoshio IMAI \\ Department of Textile and Polymeric Materials, \\ Tokyo Institute of Technology, Ookayama, \\ Meguro-ku, Tokyo 152, Japan
}

(Received October 11, 1983)

\begin{abstract}
KEY WORDS Phase Transfer Catalyzed Reaction / Polycondensation / Phase Transfer Catalyst / Bishalomethyl Aromatic Compounds / Poly $((p-$ xylylidene) / Poly(xylylene) /
\end{abstract}

During our investigation on the synthesis of polyethers by the phase transfer catalyzed (PTC) polycondensation of $\alpha, \alpha^{\prime}$-dichloro- $p$-xylene (DCPX) with bisphenols, a yellow, insoluble polymer, supposedly poly( $p$-xylylidene), was obtained as a by-product in a mixed solvent system of dimethyl sulfoxide (DMSO) and other organic solvents. ${ }^{1}$ Tetrahydrofuran (THF)-DMSO/50\% aqueous $\mathrm{NaOH}$ system was found to be one of the optimum systems for the PTC polycondensation of DCPX with bisphenols, affording high molecular weight polyethers.

DCPX has been reported to give $\operatorname{poly}(p$ xylylidene) by the PTC method in the presence of a quaternary ammonium salt such as tetrabutylammonium chloride or benzyltriethylammonium chloride. $^{2}$ A benzene $/ 50 \% \mathrm{NaOH}$ system was found very effective in giving the polymer in a high yield. We also carried out the PTC polycondensation of DCPX in the THF-DMSO $/ 50 \% \mathrm{NaOH}$ system, obtaining poly ( $p$-xylylidene) even without a phase transfer catalyst. In the following, we report the results of the PTC polycondensations of DCPX and other bishalomethyl aromatic compounds.

\section{EXPERIMENTAL}

The following abbreviations for materials have been used.

$\alpha, \alpha^{\prime}$-Dichloro-o-xylene (DCOX), $\alpha, \alpha^{\prime}$-dichloro$m$-xylene (DCMX), $\alpha, \alpha^{\prime}$-dichloro- $p$-xylene (DCPX), $\alpha, \alpha^{\prime}$-dibromo-p-xylene (DBPX), 9,10-bischloro- methylanthracene (BCMA), 4,4'-bischloromethyldiphenyl ether (BCMDPE), benzyltriethylammonium chloride (BTEAC), benzyltriethylammonium bromide (BTEAB), benzyltriethylammonium iodide (BTEAI), tetrabutylammonium chloride (TBAC), tetrabutylammonium bromide (TBAB), cetyltrimethylammonium chloride (CTMAC), tetrahydrofuran (THF), dimethyl sulfoxide (DMSO), and $N$-methyl-2-pyrrolydone (NMP).

\section{Materials}

DCPX and DBPX were recrystallized from dry benzene, and DCOX and DCMX were purified by distillation. BCMA and BCMDPE were prepared according to the method of Miller, Amidon, and Tawney $^{3}$ and the method of Tomita and Takahashi, ${ }^{4}$ respectively. Quaternary ammonium salts were used as received. An aqueous alkaline solution was prepared just before use.

\section{Polymerization}

A typical reaction procedure was almost the same as previously reported, ${ }^{1 \mathrm{~b}}$ but $0.9 \mathrm{~g}(5 \mathrm{mmol})$ of DCPX, $0.23 \mathrm{~g}(1 \mathrm{mmol})$ of BTEAC, $20 \mathrm{ml}$ of a mixture of THF and DMSO (3:1), and $20 \mathrm{ml}$ of $50 \%$ aqueous sodium hydroxide solution were used. The reaction was carried out with vigorous stirring at $60^{\circ} \mathrm{C}$ for $2 \mathrm{~h}$. A yellow polymer began precipitating in a few minutes after the addition of sodium

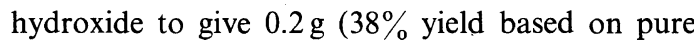
xylylidene structure) of a bright yellow polymer after $2 \mathrm{~h}$ of reaction which fluoresced brilliantly 
green-yellow. This polymer was infusible and insoluble in common organic solvents. The thermogravimetry (TG) of the polymer showed reasonable thermal stability and a $10 \%$ weight loss occurred at $300^{\circ} \mathrm{C}$ in nitrogen. The infrared spectrum of the polymer was identical to that of authentic poly $(p$ xylylidene) prepared according to the method of Gilch and Wheelwright. ${ }^{5}$ It exhibited absorptions at $825 \mathrm{~cm}^{-1}$ ( $p$-disubstituted benzene ring) and 960 $\mathrm{cm}^{-1}$ (trans $-\mathrm{CH}=\mathrm{CH}-$ ). Elemental analysis gave the following results: $\mathrm{C}, 77.11 \% ; \mathrm{H}, 5.24 \% ; \mathrm{N}, 0 \%$; $\mathrm{Cl}, 16.50 \%$. The structure best fitting to these values is

$$
\begin{aligned}
\left.\mathrm{ClCH}_{2}+\mathrm{C}_{6} \mathrm{H}_{4}-\mathrm{CH}=\mathrm{CH}\right]_{3} \\
\left.\quad+\mathrm{C}_{6} \mathrm{H}_{4} \mathrm{CH}_{2} \mathrm{CHCl}\right]_{1} \mathrm{C}_{6} \mathrm{H}_{4} \mathrm{CH}_{2} \mathrm{Cl}
\end{aligned}
$$

\section{RESULTS AND DISCUSSION}

DCPX was known to give poly ( $p$-xylylidene) in a high yield by PTC polycondensation in benzene $/ 50 \% \mathrm{NaOH}$ system with TBAC or BTEAC. ${ }^{2}$ However, no polymer was obtained without quaternary ammonium salts. We found that not only DCPX but also other bishalomethyl aromatic compounds gave polymers in the THF-DMSO $/ 50 \%$ $\mathrm{NaOH}$ system even without quaternary ammonium salts. Various bishalomethyl aromatic compounds possibly underwent PTC polycondensation to give polymers with the following structures:

$$
\begin{aligned}
\left.\mathrm{XCH}_{2}-\mathrm{Ar}-\mathrm{CH}_{2} \mathrm{X} \rightarrow \mathrm{XCH}+\mathrm{Ar}-\mathrm{CH}_{2} \mathrm{CHX}\right\rfloor_{m} \\
+\mathrm{Ar}-\mathrm{CH}=\mathrm{CH} \dashv_{n} \mathrm{Ar}-\mathrm{CH}_{2} \mathrm{X}
\end{aligned}
$$

$\mathrm{X}: \mathrm{Cl}, \mathrm{Br}$

Ar :

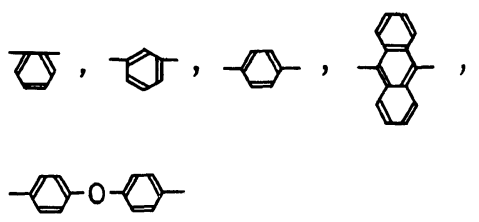

where the $m$ and $n$ values greatly depend on both the alkaline concentration used in the PTC system and the structure of the monomer.

Table I shows the results of polycondensation of DCPX in the presence of various quaternary ammonium salts. Although DCPX polymerized without a phase transfer catalyst, yield of the polymer was low. The addition of a phase transfer catalyst obviously enhanced the polycondensation of DCPX
Table I. The PTC polycondensation of DCPX

\begin{tabular}{|c|c|c|c|}
\hline \multirow{3}{*}{ Run } & \multirow{3}{*}{$\begin{array}{c}\text { Quaternary } \\
\text { ammoniun } \\
\text { salt }\end{array}$} & \multicolumn{2}{|c|}{ Yield } \\
\hline & & \multicolumn{2}{|c|}{$\%$} \\
\hline & & $A^{a}$ & $\mathrm{~B}^{\mathrm{b}}$ \\
\hline $1-1$ & - & 10 & 6 \\
\hline $1-2$ & BTEAC & 21 & 12 \\
\hline $1-3$ & BTEAB & 29 & 17 \\
\hline $1-4$ & BTEAI & 54 & 31 \\
\hline $1-5$ & TBAC & 24 & 14 \\
\hline $1-6$ & TBAB & 51 & 30 \\
\hline $1-7$ & CTMAC & 20 & 12 \\
\hline $1-8$ & BTEAC $^{c}$ & 35 & 20 \\
\hline $1-9$ & BTEAC $^{d}$ & 12 & 7 \\
\hline $1-10$ & BTEAC $^{\mathbf{e}}$ & 8 & 5 \\
\hline
\end{tabular}
in a THF-DMSO $/ 50 \% \mathrm{NaOH}$ system in the presence of various quaternary ammonium salts

a Based on the xylylidene structure.

b Based on the amount of monomer in the feed.

c $10 \mathrm{mmol}$ of sodium chloride was added in an aqueous phase.

d $40 \% \mathrm{NaOH}$ was used.

e $30 \% \mathrm{NaOH}$ was used.

and the yield of the polymer was improved very much. However, our results, with respect to polymer yield, were inferior to those reported. ${ }^{2}$ It is interesting to note that the yield of the polymer decreased in the order of BTEAI > BTEAB > BTEAC, this being the reverse order of the catalytic effect for the polycondensation of DCPX with bisphenols by the PTC method. ${ }^{6}$ TBAC was reported to give an almost quantitative yield of poly ( $p$-xylylidene) in the benzene $/ 50 \% \mathrm{NaOH}$ system. ${ }^{2}$ However, TBAC and CTMAC gave almost the same results as BTEAC in the THF-DMSO/ $50 \% \mathrm{NaOH}$ system. According to these results, the optimum polycondensation of DCPX may depend primarily on the particular organic solvent system used.

When inorganic salts such as sodium chloride were added in an aqueous solution (run $1-8$ ), the polymer yield increased. This is considered one of the salting-out effects; hydroxide anions were forced to transfer into an organic phase, causing the reaction to proceed much faster.

Concentration of alkali also affected the reaction (run 1-2, 1-9, and 1-10). A higher concentration 
Table II. The PTC polycondensation of DCPX in various organic solvents $/ 50 \% \mathrm{NaOH}$ system $^{\mathrm{a}}$

\begin{tabular}{|c|c|c|c|c|c|c|c|}
\hline \multirow{2}{*}{ Run } & \multicolumn{4}{|c|}{ Organic solvent } & \multirow{2}{*}{$\frac{50 \% \mathrm{NaOH}}{\mathrm{ml}}$} & \multicolumn{2}{|c|}{ Yield $/ \%$} \\
\hline & & $\mathrm{ml}$ & & $\mathrm{ml}$ & & $A^{b}$ & $\mathrm{~B}^{\mathrm{c}}$ \\
\hline $2-1$ & - & & - & & 40 & 7 & 4 \\
\hline $2-2$ & - & & DMSO 2 & 20 & 20 & 74 & 43 \\
\hline $2-3$ & Benzene & 20 & - & & 20 & 61 & 36 \\
\hline $2-4$ & Benzene & 15 & DMSO & 5 & 20 & 59 & 34 \\
\hline $2-5$ & Nitrobenzene & 20 & - & & 20 & Trace & Trace \\
\hline $2-6$ & Nitrobenzene & 15 & DMSO & 5 & 20 & Trace & Trace \\
\hline $2-7$ & Anisole & 20 & - & & 20 & 55 & 32 \\
\hline $2-8$ & Anisole & 15 & DMSO & 5 & 20 & 55 & 32 \\
\hline $2-9$ & THF & 20 & - & & 20 & 24 & 14 \\
\hline $2-10$ & THF & 20 & DMSO & 5 & 20 & 37 & 21 \\
\hline $2-11$ & NMP & 20 & - & & 20 & 52 & 30 \\
\hline $2-12$ & NMP & 20 & DMSO & 5 & 20 & 70 & 41 \\
\hline
\end{tabular}

a The reaction was carried out with $5.0 \mathrm{mmol}$ of DCPX in the presence of BTEAC.

b Based on the xylylidene structure.

c Based on the amount of monomer in the feed.

of sodium hydroxide afforded a high yield of the polymer with an almost exclusively $p$-xylylidene structure, whereas a low concentration gave a polymer with both the $\alpha$-chloro- $p$-xylylene and $p$ xylylidene structures. It is interesting that DCPX predoninantly gave white, soluble poly $(\alpha$-chloro- $p$ xylylene) when $40 \% \mathrm{KOH}$ was used, while a yellow, insoluble poly ( $p$-xylylidene) was obtained when $50 \% \mathrm{KOH}$ was used. The addition of DMSO led to the successful synthesis of a high molecular weight polyether from DCPX and 2,2-bis(4-hydroxyphenyl)propane by the PTC method ${ }^{1 \mathrm{a}, \mathrm{b}}$; consequently, the effects of DMSO were examined in various organic solvent systems.

Table II shows solvent effects for the PTC polycondensation of DCPX in the presence of BTEAC. Addition of DMSO enhanced the reaction very much. Sulfoxides such as DMSO and polysulfoxides are known to act as phase transfer catalysts. $^{7}$ Furthermore, DMSO is known to enhance the reactivity giving poly ( $p$-xylylidene $){ }^{2} \mathrm{~A}$ mixed solvent system containing DMSO should therefore be a good solvent system. This is because DMSO probably functions as both a phase transfer catalyst and dehydrochlorination catalyst to give $\operatorname{poly}(p-$ xylylidene). Although the benzene $/ 50 \% \mathrm{NaOH}$ system of run $2-3$ was in good agreement with the results reported, ${ }^{2}$ a nitrobenzene $/ 50 \% \mathrm{NaOH}$ sys- tem yielded only a trace amount of the polymer.

DCOX, DCMX, DBPX, BCMA, and BCMDPE also gave polymers by the TPC method. The results are summarized in Table III. DCPX resulted in an insoluble polymer, while all the other polymers were soluble in NMP. The polymers given by DBPX and DCMX should be considered poly(xylylene)s since they showed almost the same thermal properties as those of poly ( $\alpha$-chloro- $p$-xylylene). The total values obtained from elemental analysis did not come to 100 , and thus the hydrolysis of halomethyl group is considered to have taken place to a certain extent and the polymers possibly contained both ether linkages and hydroxyl end groups. The inherent viscosities of the polymers were less than 0.16 $\mathrm{dlg}^{-1}$, indicating that oligomerization and hydrolysis reactions took place competitively in the PTC polycondensation reactions.

\section{REFERENCES}

1. a) N. Yamazaki and Y. Imai, Polym. Prepr., Jpn., 31, 1429 (1982); b) N. Yamazaki and Y. Imai, Polym. J., 15, 603 (1983).

2. S. Hashimoto, T. Furukawa, and H. Yamamoto, Kobunshi Ronbunshu, 35, 685 (1978).

3. M. W. Miller, R. W. Amidon, and P. O. Tawney, $J$. Am. Chem. Soc., 77, 2845 (1955). 
N. YAMAZAKI and Y. IMAI

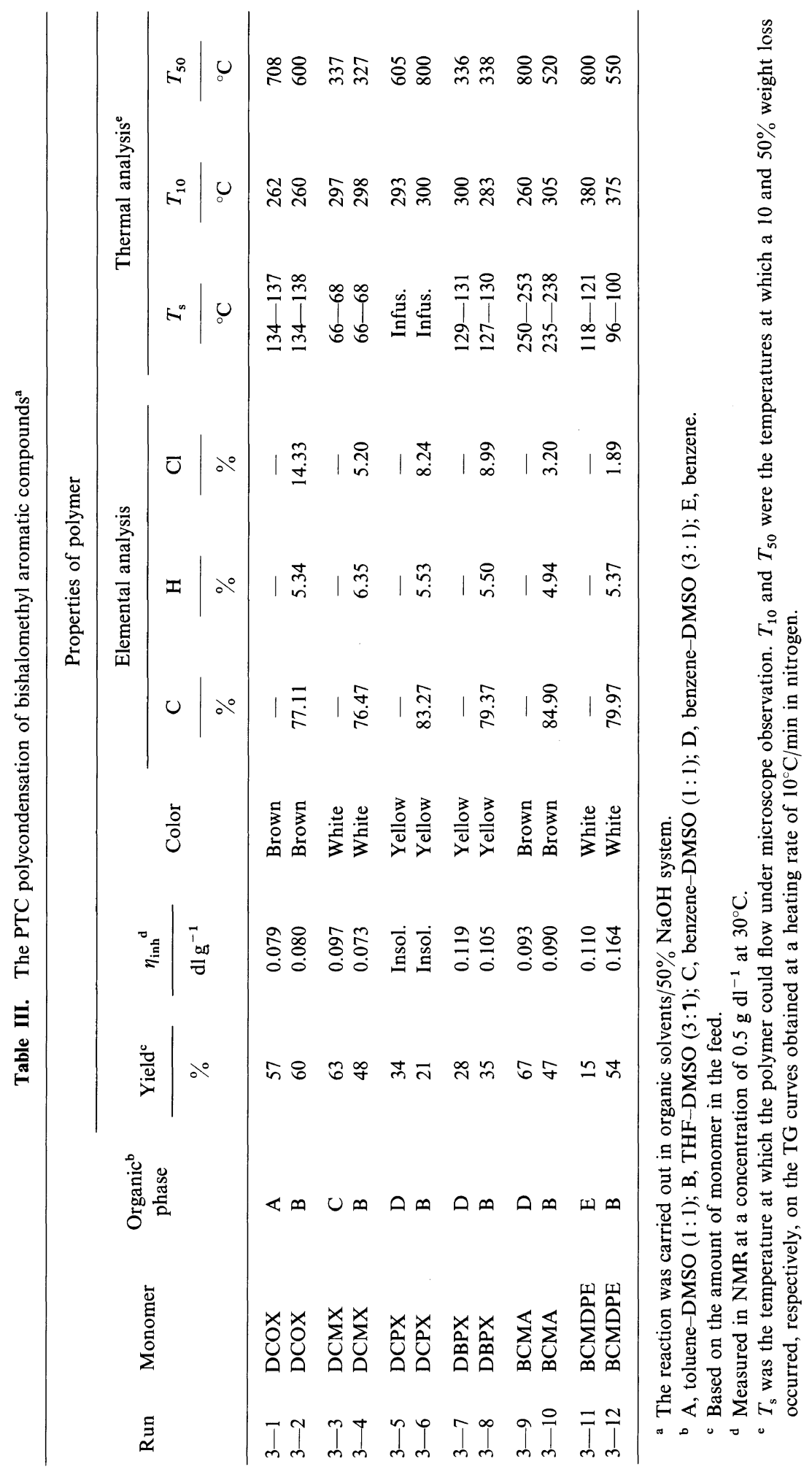




\section{Phase Transfer Catalyzed Polycondensation}

4. M. Tomita and K. Takahashi, J. Pharm. Soc., Jpn., 73, 760 (1953) [Chem. Abstr., 48, 6984 (1954)].

5. H. G. Gilch and W. L. Wheelwright, J. Polym. Sci., A-1, 4, 1337 (1966).
6. N. Yamazaki and Y. Imai, Polym. Prepr., Jpn., 32, 161 (1983).

7. K. Ohta, Y. Masuda, S. Kondo, and K. Tsuda, Polym. Prepr., Jpn., 32, 401 (1983). 